\title{
Situación lingüística, social y política del catalán
}

\author{
IV Jornadas de lenguas y literaturas catalana, gallega y vasca \\ Universidad Autónoma de Madrid \\ Universidad Nacional de Educación a Distancia (Madrid) \\ Universidad de Alcalá de Henares \\ 24-IV-1991
}

\section{JOAN SOLÀ}

UNIVERSIDAD DE BARCELONA

En el programa figura para mi conferencia un título macabro que yo no escogí ("Vida y muerte del catalán"): simplemente lo encajé de los organizadores a través del hilo telefónico. Lo mismo le sucedería a mi colega vasco, el señor Atxaga. A la postre ha resultado que los gallegos, representados por el señor Alonso Montero, pasan en el impreso por menos necrofílicos, cuando lo que son es menos sumisos, y con mucha honra. Aclarado el malentendido, el nuevo título responde a lo que pretendo desarrollar.

Me propongo hablarles, sin mucha profundidad, de tres aspectos de la lengua catalana actual: el lingüístico propiamente dicho, el social y el político. Yo no soy especialista en los dos últimos, aunque sí sé algo del primero. Pero hoy estos tres aspectos están de rigurosa actualidad en nuestro mundo pequeñísimo, que a nosotros a veces nos parece grande, sobre todo cuando somos protagonistas de algo, por ejemplo de las eternas y recurrentes discusiones sobre la salud interna (lingüística) o externa (social y política) de la lengua. En ese Liliput es muy fácil ser cabeza de ratón: basta con ser, por ejemplo, catedrático de lengua catalana de la Universidad y tener, además, una columna en un periódico, una cierta vanidad y ganas de intervenir en la vida pública. Todo lo cual se cumple en quien les habla y, bien revuelto, hace un cóctel que más de una vez produce fuertes indigestiones o por lo menos taquicardias no siempre fáciles de calmar.

Para que vean lo movido que está este nuestro mundillo socio-políticolingüístico, les diré que entre los recientes meses de octubre y marzo se han publicado (según mis noticias) nueve libros esencialmente polémicos sobre la salud del catalán (los de Pazos, Vallverdú, Prats-Rafanell-Rossich, Sabater, Reixach, Royo, Joan, Burguera y Actes), algunos de ellos con dos, y hasta tres 
ediciones (tres los de Pazos y Prats-Rafanell-Rossich); y me constạ que hay por los menos dos más en prensa o buscando editor. No menciono los innumerables artículos en la prensa y cartas al director, a que nuestra comunidad es muy aficionada. Por fin, y no me dirán que no les sitúo en el ajo del asunto, en estos momentos en que yo les hablo se está sancionando en nuestro Parlament autonómico una también polémica ley que confiere autoridad en materia linguística al Institut d'Estudis Catalans, nuestra academia de la lengua.

\section{SITUACIÓN LINGÜÍSTICA}

La situación lingüística del catalán tiene dos aspectos claramente diferenciados: por una parte, vamos a ocuparnos del largo esfuerzo realizado desde mediados del siglo XIX hasta estos mismos momentos, a la búsqueda de un modelo lingüístico aceptable; y, en segundo lugar, nos ocuparemos del estado de la lengua en estos momentos por lo que se refiere a la conservación de su personalidad linguística. Como es evidente, ambos aspectos están inextricablemente relacionados.

\subsection{Hacia un MOdelo lingüístico}

El año 1859 se restableció en Barcelona una fiesta poética medieval, que tomó el nombre de Jocs Florals. Al principio eran concursos poéticos en que se premiaban composiciones que cantaran el amor, la patria y la fe. Con los años la temática y la participación fue más compleja, a la vez que la importancia de la fiesta disminuía porque el catalán iba adquiriendo nuevas parcelas. Pero al principio aquel acontecimiento era el único en todo el año en que el catalán se usaba en público. Las actas recogían toda la producción y los discursos que la arropaban: todo en catalán. Por lo cual, esta lengua, que llevaba siglos sin cultivo literario (por lo menos digno de tal nombre) tuvo que pensar, inmediatamente, en una ortografía y enseguida en una gramática y un diccionario. Ninguna de las tres cosas se consiguió de forma socialmente aceptada hasta el primer tercio del siglo XX: realizó las tres tareas un lingüista providencial llamado Pompeu Fabra, que se impuso por sus profundos conocimientos, sus dotes didácticas, su visión política de la lengua y otras cualidades.

Los poetas de los Jocs Florals usaban una lengua insegura, más emocionante que real, mezcla de palabras y formas antiguas y de castellanismos pro- 
venientes de su educación. Pronto el catalán conquistó los teatros, y entonces, por los años sesenta, surgió un autor cómico tan prolífico como Lope de Vega, que en horas veinticuatro ponía las musas en escena y siempre llenaba las salas. Se llamaba Frederic Soler, y firmaba Pitarra. Las llenaba porque usaba el lenguaje de la calle, el que era capaz de hacer olvidar a aquellas gentes las penas diarias. En las portadas de las piezas teatrales explícitamente hacía constar que estaban compuestas en verso "i en el català que ara es parla". Puede que más por la envidia de sus éxitos que por otra cosa, los "otros", es decir, los poetas y demás escritores serios, empezaron pronto a escandalizarse, le acusaron de traidor a la patria lengua y le mantuvieron proscrito de la buena sociedad. La lengua de la calle les parecía, por definición, chabacana, proletaria, indigna de las prensas y de los salones. Los que compartían la herejía de que la lengua sirve para comunicarse, para hacer campaña política, teatro y novela - y no sólo para cantar el amor el domingo por la tarde después de la siesta - aumentaban día a día, y no únicamente en Cataluña, sino también en el País Valenciano. En Valencia se publicaron en ese siglo numerosas revistas humorísticas escritas en un lenguaje notablemente más degenerado o híbrido: sus directores y redactores tenían una idea mucho más primaria y pragmática de la lengua, y así lo hacían constar si a alguien - a casi nadie allí- le nacía algún escrúpulo purista. En Cataluña todo el mundo aceptaba, a pesar de todo, y aunque con matices ideológicos a menudo bastante dispares, que la lengua era, además, un valor cultural que había que salvaguardar.

La polémica duró hasta finales de siglo. De hecho hasta que Fabra empezó a plantearse la cuestión doble de para qué tenía que servir el catalán y de qué catalán tenía que ser ése: si el clásico, el de los siglos en que casi no se escribía o el real y popular del momento. A ambas preguntas respondió con mucha más ambición que los cantores de la patria, y precisamente en la línea de los proscritos: el catalán tenía que servir para los discursos políticos, la Universidad, la prensa diaria, la novela, la misa y la diversión; y la lengua que había que rehabilitar para estos usos era la lengua real, previamente saneada y fortalecida a imagen de las demás lenguas de cultura de Europa.

Un programa fácil de describir a posteriori, pero dificilísimo de llevar a la práctica: de hecho la lengua literaria moderna no se consolidó hasta los años veinte de este siglo y concluyó en 1932 con la publicación del diccionario que desde entonces se considera normativo. En este primer tercio de siglo la cultura catalana atravesó momentos de gran euforia y contó con numerosos escritores de exquisita sensibilidad lingüística, los cuales fueron tan importantes como el gramático para la consolidación de esta lengua moderna, fenómeno que nosotros y todos los entendidos consideramos una empresa titánica y una proeza nacional. Si desde mediados del siglo XIX la lengua fue símbolo del pueblo catalán, mucho más lo fue a partir de la reforma, puesto que nos podemos enorgullecer de su modernidad, dignidad y riqueza.

La euforia duró poco y le siguió la más larga y oscura noche de nuestra historia. En los primeros años del posfranquismo, cuando se pudo volver a 
publicar algo, primero en la clandestinidad y después más libremente, la media docena de personas en cuyas manos estuvo la lengua y la cultura se preocuparon escrupulosamente de transmitir a las nuevas generaciones la lengua que antes de la guerra había quedado fijada. Los tiempos avanzaban, las costumbres cambiaban, nuevas gentes se instalaban en el territorio catalán y aquella lengua empezaba a experimentar dificultades de adaptación: los viejos códigos se quedaban estrechos y los sacerdotes que cuidaban el fuego sagrado para transmitirlo intacto a las nuevas generaciones hacían mil filigranas para hacer decir a los nuevos novelistas lo que querían pero en una lengua genuina, sin neologismos y sobre todo sin castellanismos. Los viejos diques aguantaban la presión como podían, pero ya en los años cincuenta varios escritores chocaron frontalmente con los correctores y se reprodujo la vieja polémica: el catalán de la calle contra el catalán de los códigos de los años veinte. Hay que entender que es exactamente la misma polémica, puesto que se produce por las mismas causas - urgencia de adaptar la lengua a las necesidades comunicativas - y por las mismas posiciones ideológicas - la lengua es tan sólo o primariamente un medio de comunicación, o es primariamente un instrumento y un objeto de cultura, además de símbolo de un pueblo o de una patria.

Se pasó la maroma como se pudo y llegamos a finales de los años setenta. En ese tiempo se produce uno de los cambios más espectaculares de toda nuestra historia en el terreno que nos ocupa: de no tener casi ninguna presencia pública (excepto en los libros, en la canción y algo en el teatro), el catalán pasó en seis o siete años a tener una presencia pública y oficial aparentemente universal. Digo aparentemente porque, en primer lugar, lo que se consiguió en las islas Baleares y en el País Valenciano fue siempre mucho menos y mucho más tardíamente que lo conseguido en Cataluña; y en segundo lugar, porque de lo dicho o entredicho en los papeles a lo hecho en la realidad siempre ha habido grandísimo trecho. Globalizando y siendo optimistas, se consiguió la escuela, el uso oficial y una presencia notable en los medios de comunicación (véanse los detalles enumerados en Vallverdú 34-36).

Si en los años cincuenta la lengua necesitaba imprescindiblemente abrir puertas, es fácil imaginar lo que pasó a finales de los setenta y desde entonces hasta hoy. Los cambios sociales han sido mucho más rápidos e incluso efímeros; las personas empleadas en el quehacer linguístico pasaron de dos docenas a miles (profesores, traductores, asesores de los medios de comunicación y de empresas de todo tipo, guionistas, correctores); la televisión, la radio, los periódicos, el Parlamento obligaron a trabajar con rapidez y sin excesivos escrúpulos ideológicos: primum vivere; las rotativas no esperan y el micrófono y la pequeña pantalla consumen más y más variada lengua en un día que toda la prensa anterior en medio año. Y no olvidemos que en Cataluña se había producido la inmigración más importante y rápida de toda su historia: en el entorno de Barcelona, donde se concentra la mitad de la población total, la inmigración ha llegado a superar el $50 \%$. Si no habláramos de lengua, 
habría que recordar la vergonzosa precariedad y el hacinamiento en que muchos inmigrados tuvieron que vivir. Si volvemos a la lengua, no podemos dejar de decir que esos millones de personas se asimilaron mal o nada al nuevo entorno.

Se veía venir la tormenta. Los medios de comunicación fueron asesorados por las nuevas generaciones, que no pudieron conjugar los viejos ideales de la pureza lingüística con las polifacéticas y urgentes necesidades de los monstruos modernos de comunicación; además, las nuevas generaciones ya se sabe que tienen una sensibilidad y una ideología que no siempre coinciden con las de las generaciones resistenciales que les precedieron, porque para ellos es mucho más importante el futuro que el pasado. Los conservadores se rasgaban las vestiduras cada vez que se perdía una cedilla, una distinción semántica o un contraste fonético. Los asesores respondían que en la televisión y en los teletipos la gente hablaba así y que no podían dar la vuelta a la sociedad como a un guante. Además, a nuevos usos, a nuevos modismos, nuevas dudas sobre si existían o no en los códigos clásicos o sobre si había que adoptarlos o adaptarlos y cómo.

Esta vez la polémica se bifurcó y se hizo más virulenta si cabe. Por una parte, se fueron conformando los libros de estilo de los varios medios de comunicación, donde la lengua ocupaba siempre la parte central y crucial. Centenares de ojos se mantenían al acecho para descubrir en ellos y denunciar palabras o construcciones nefandas. Por otra parte, las riñas de gallos que en los años cincuenta se celebraban en el patio interior de la única revista catalana existente (Serra d'Or, que leían sólo las minorías selectas y eruditas), ahora se convertían en libros, algunos de los cuales se confeccionan rápidamente y por tanto fácilmente acogen incluso insultos personales. El mercado se frota las manos y la fauna se multiplica. La espiral ha llegado en estos últimos meses a la locura, de la cual sólo se han librado los ciegos, sordos y mudos, triste recompensa. La ley que en estos momentos se está votando en nuestro Parlament es también en parte, a mi modo de ver, fruto de estos largos nerviosismos.

Auténtico drama de familia que sólo pueden entender quienes, como nosotros, tienen la triste suerte de no poder vivir tranquilos con su lengua. De todas formas, también aquí puede anidar algún pensamiento optimista: en definitiva, todo lo que acaban de oír refleja una vida auténtica dentro de nuestra comunidad lingüística, vida que muchas otras comunidades pequeñas quisieran para sí. Y además de vida para la lengua, hay vida para los millares de personas que trabajan en ella en los oficios que he enumerado y en otros.

Ésta ha sido, más o menos, la larga lucha por encontrar un modelo de lengua. Veamos el otro aspecto del estado lingüístico del catalán: la calidad de la lengua de la calle. 
Hasta muy recientemente este aspecto se confundía con el anterior. Era un mal endémico secular bien conocido y hasta aceptado que los catalanes sabíamos mal nuestra lengua. ¿Cómo íbamos a saberla si no se nos enseñaba ni se nos permitía usarla más que a hurtadillas? Los antídotos eran los libros de barbarismos, que en nuestro dominio lingüístico han proliferado de forma espectacular y hasta morbosa. En estos libros se recoge absolutamente todo lo que alguien puede decir o ha dicho efectivamente mal. Si tienen en cuenta lo variopinto de nuestra comunidad actual, comprenderán que haya tratados de barbarismos que casi recogen toda la lengua: porque en cada umbral, en cada paso a nivel, en cada piedra de la calle, en cada farola puede haber alguien, de casa o forastero, que vacile o tropiece. Por lo mismo, es fácil entender que tales antídotos sólo sirven para hacer compañía a los otros lazarillos lingüísticos que todo catalán que se precie tiene en una estantería de su casa. Para poco más: cuando no llevas corbata, cuando no estás en el aula, hablas como puedes. Que es lo que, de todas formas, hacen tus hijos, que no han nacido para salvar la lengua de nadie. Ni las señoras del mercado, ni los vendedores a domicilio. ¿Y cómo habla la gente de la calle?

Si en otros aspectos de la temática que nos ocupa hay divergencias entre mi interpretación de la realidad y la que otros colegas podrían ofrecerles, en éste creo que no la hay. Creo ser objetivo si les digo que la calidad de la lengua preocupa hoy de forma extremadamente seria a todos los que nos dedicamos a ella: profesores de todos los niveles, asesores de editoriales o de medios de comunicación, investigadores, etcétera. Lo difícil es darles a ustedes una idea ni siquiera vaga del desastre ecológico. Voy a intentarlo valiéndome de las observaciones de uno de los libros recientes a que me he referido (PratsRafanell-Rossich 68-75). Prescindiré de describir la devastación anterior y me centraré exclusivamente en hechos rigurosamente actuales. Es decir, a lo que les voy a dejar entrever, sumen ustedes lo sucedido durante los siglos anteriores.

Si yo pronuncio la secuencia castellana los haberes, ustedes advertirán inmediatamente que no soy castellanohablante nativo: entre otras deficiencias, pronuncié sonora, en lugar de sorda, la $s$ del artículo, porque en catalán ésta es una regla elemental que absolutamente nadie deja de practicar. Ustedes no distinguen entre los haberes "el dinero ahorrado" y los saberes "lo que se sabe"; nosotros sí distinguimos entre els avis "los abuelos" y els savis "los sabios". Pues bien, hoy muchos catalanohablantes empiezan a no distinguir las vocales abiertas de las cerradas y las varias parejas de consonantes sonoras y sordas. Se trata, como les digo, de lo más elemental y básico de nuestra fonética.

En sintaxis hay un fenómeno tan básico, universal y, por tanto, distintivo como el que hemos comentado de la fonética. Son los pronombres hi y en. 
Donde ustedes dicen "Debería ir pero no iré", un catalán dirá siempre sin ningún asomo de duda "Hi hauria d'anar però no hi aniré". Donde ustedes dicen "Tengo dos negros y uno blanco", nosotros no podemos dejar de decir, ni que queramos, "En tinc dos de negres i un de blanc". Pueden estar ustedes hablando un cuarto de hora en un catalán perfecto: como se dejen un solo pronombre de éstos delatarán su origen no catalán. Pues bien: hoy estos pronombres están empezando a faltar de manera rápida y alarmante. Desde luego se los dejan los que no nacieron entre nosotros, pero ya incluso los que sí nacieron.

Además de este fenómeno, nuestra sintaxis va perdiendo todos los días nuevos rasgos distintivos, presionada por la castellana: los relativos, las oraciones subordinadas, las construcciones optativas, etcétera.

El léxico es, como se sabe, la parte más vulnerable de una lengua, probablemente porque tiene una estructura menos trabada, más atomizada. Les ahorro ejemplos vulgares y les ofrezco unos más significativos. En los siguientes términos castellanos nosotros distinguimos matices semánticos o contextuales que expresamos con parejas de términos diferentes: a grande respondemos con gros (aplicado a objetos en que no interesa la capacidad: una roca, un dedo, una medalla) o con gran (aplicado a objetos en que interesa la capacidad física o afectiva: una casa, un campo de maíz, el corazón); a luz respondemos con el llum (masculino: objeto) o la llum (energía); a secar, con eixugar (aplicado a humedad no intrínseca: los platos, la ropa) o assecar (para la humedad intrínseca de un árbol o del cerebro de Don Quijote); al verbo probar(se) del castellano respondemos con emprovar-se (un traje), provar (fortuna; intentar) o tastar (una comida), etcétera. En cambio, no distinguimos entre trucha y tortilla, etcétera. Hoy todo esto se está igualando ante nuestros ojos atónitos e impotentes: desde luego, la igualación se hace en el sentido del castellano. No todas la palabras se han perdido o sufren descalabros. Hoy todavía nadie dice perro por gos: gos es un animal todavía muy presente en la sociedad. Pero esta presencia no es protección suficiente. Basta con que se añada una circunstancia afectiva o de grupo o de cualquier otro género para que bolquers sea borrado del mapa por panyals (que son los pañales castellanos), para que grapejar retroceda ante sobar. Si se trata del mundo vegetal o animal, en casos menos evidentes que el mencionado, ya nadie sabe otros nombres que los castellanos ardilla o seto. Y no nos metamos en terrenos todavía más específicos. "Ciertamente — dice el libro aludido-, unos pocos ejemplos no demuestran gran cosa; pero ¿qué sucede cuando son centenares los que se podrían aducir en el mismo sentido?" Desde mi conocimiento de la realidad, me atrevería a decir que la mitad del léxico habitual en un hombre de la calle está hoy, por lo menos en muchísimas personas y en muchos ambientes, en el trágico estado descrito.

Y si del léxico aislado pasamos a la fraseología y a los refranes, el porcentaje pasa, sin ningún género de duda, al $75 \%$ o al $90 \%$. Los refranes, robusto fondo de reserva de una lengua sana, hoy han desaparecido casi por completo, cuando a finales del siglo XIX tenían una vivencia y una abundan- 
cia comparables a las de cualquier lengua. En cuanto a fraseología, la desorientación es absolutamente general e inevitable en las circunstancias en que mi lengua vive. Ayer oí en la radio oficial de Cataluña "No és res de l'altre dijous" ("No es nada del otro jueves"). Yo mismo un día utilicé en un artículo, creyéndola catalana, la frase a trancas y barrancas (con las terminaciones en catalán, claro): por suerte, la desconfianza que todo catalán lleva siempre a flor de piel me hicieron abrir un diccionario y no llegó el desliz a la imprenta. Pero consideren ustedes cuál puede ser el futuro de una lengua que está perennemente en la uvi, al cuidado paciente de enfermeros-correctores-diccionarios.

Como les dije, aquí todo el mundo coincide en el diagnóstico. Una vez ha reconocido que éste es un aspecto que a todo el mundo alarma pero del que no tenemos datos recogidos de manera ordenada, Reixach, uno de nuestros sociólogos con más orientación hacia la esperanza, salpica su reciente estudio estadístico sobre el conocimiento del catalán de frases como la siguiente: "La situación se complica todavía más cuando llegamos al terreno del uso oral y escrito, en el que, además de amplias y graves lagunas permanentes, se producen situaciones auténticamente kafkianas de alternancias y mezclas en la utilización personal, familiar y social de la lengua" (página 144; otras referencias: páginas $8,135,143,145,147)$. Les puedo añadir que hay un programa de radio diario de una hora de duración en que, partiendo teóricamente del catalán, dos personajes pasan revista a la actualidad divina y humana en un tono humorístico y en un lenguaje exactamente y dramáticamente comparable al de las revistas de humor valencianas del siglo pasado de las que les hablé más arriba. El efecto radiofónico es excelente, pero quienes estamos de guardianes de la uvi no podemos evitar que la rabia nos desborde. Así vivimos algunos catalanes, respetables universitarios de Alcalá. Déjenme aclarar que procuramos que los árboles no nos oculten el bosque y que la concentración en nuestra profesión no salpique el resto de nuestra vida, la copa con los amigos, el aire puro que los domingos buscamos en nuestros maravillosos montes, la lectura de nuestros excelentes poetas, el avión de bricolaje que ayudamos a construir a nuestra hija.

\section{SITUACIÓN SOCIAL}

Aquí es donde los catalanohablantes hemos trabajado más durante los últimos años, de tal manera que muchos de nuestros sociolingüistas son conocidos por el mundo. Creo que poseemos excelentes interpretaciones teóricas, además de una cantidad muy notable de análisis de la realidad. No puedo intentar darles una idea de este mundillo: me desviaría mucho de las líneas que debo seguir para que mi exposición sea clara y concluyente. 
La sociolingüística en principio estudia las condiciones y las vicisitudes de una lengua respecto a la sociedad que la habla. Uno de los aspectos más centrales de esta ciencia es la extensión diacrónica y sincrónica de la lengua. los progresos o retrocesos geográficos y sociales. Otros aspectos son, por ejemplo, la relación entre lengua y la edad o el sexo o las varias situaciones sociales, etcétera. Los tres aspectos más relevantes hoy para el catalán son: la extensión actual de la lengua (conocimiento pasivo), el uso efectivo (conocimiento activo) y la calidad. Acabamos de referirnos a la calidad. Vamos a ocuparnos brevemente de los otros dos.

\subsection{CONOCIMILNTO PASIVO DEL CATALÁN}

Los sociolingüistas manejan infinidad de estadísticas, y a menudo el lector se ahoga en ellas, que además fácilmente admiten manipulación o por lo menos interpretaciones dispares. Intentaré resumir lo más relevante para nosotros, partiendo de trabajos recentísimos (Mapes y Reixach).

Por una parte, la llegada del catalán a la escuela y a los medios de comunicación, así como a la vida pública en general, ha producido en los últimos diez años un efecto espectacular por lo que se refiere al conocimiento del catalán en su aspecto pasivo, es decir, a la posibilidad de entender la lengua. Como en otros capítulos de mi exposición, simplifico drásticamente y sin previo aviso. Quiero decir, y de una vez por todas, que los tres territorios más importantes de la lengua catalana, la islas Baleares, el País Valenciano y Cataluña, se encuentran en condiciones incluso radicalmente diferentes en algunos puntos a que me referiré. Fundamentalmente, me referiré a Cataluña, el territorio más privilegiado a pesar de todo.

El padrón de 1986 registró por primera vez en nuestra historia datos lingüísticos de los tres territorios expresados. Constan en él cuántos entienden el catalán, cuántos, además, saben hablarlo, cuántos saben leerlo y, finalmente, cuántos saben escribirlo. Los datos dicen lo siguiente (Reixach, 137):

— Lo entiende el 91,7\% en Catalunya; el 90,4\% en Baleares, y el 86,5\% en el País Valenciano.

- Saben hablarlo el $65,8 \%$, el $71,7 \%$ y el $57,3 \%$, respectivamente.

- Saben leerlo el $63,7 \%$, el $47 \%$ y el $29,1 \%$, respectivamente.

- Saben escribirlo el $32.6 \%$, el $16,7 \%$ y el $8,1 \%$, respectivamente.

En el País Valenciano, en conjunto, poco más del 50\% pueden hablarlo. La lectura y la escritura están todavía más bajas. Para algunos sociolinguiistas 
el hecho de que puedan entenderlo una proporción tan grande de personas es de gran importancia: por ejemplo, de cara a poder favorecer la presencia pública de la lengua.

Poseemos otro dato esperanzador, también derivado del censo, aunque ahora sólo para Cataluña: en los cinco años que van de 1981 a 1986, la comprensión de la lengua pasó del $84,4 \%$ al $97,1 \%$ en las personas de diez a catorce años, lo que significa un $12,7 \%$ de aumento, cifra nada despreciable. En las otras edades el aumento superó el $10 \%$ entre los cinco y los cuarenta y cuatro años (Reixach 105). Lo cual significa que, a este ritmo, pronto se podrá decir que en Cataluña nadie tendrá impedimento para entender la lengua propia. De hecho, ya actualmente se puede decir (con el $90 \%$ aproximadamente para las edades entre diez y cincuenta años).

Ésta es una realidad evidente. Contribuye mucho al conocimiento pasivo de la lengua el hecho de que sea de la misma familia que el castellano: en un tiempo relativamente corto, cualquier persona que viva en tierras catalanas entiende forzosamente nuestra lengua, a menos que viva en guetos, que todavía los hay, o que se resista a "quererla" entender, cosa que también sucede.

Otra realidad igualmente evidente y constatada es que la lengua se está perdiendo a ritmo galopante en ciertos puntos estratégicos. Concretamente, se puede dar por perdida en las ciudades de Perpiñán y Alicante. Y está en peligro grave en las de Valencia y Palma de Mallorca (Mapes 41-42). Las causas son en general fáciles de detectar, pero no voy a entrar en ellas.

En resumen, la extensión del conocimiento del catalán atraviesa un momento delicado, especialmente en las grandes aglomeraciones urbanas, donde la inmigración, entre otros factores, tiene un gran peso. Prescindiendo de esto, en Cataluña en general, e incluso en los otros dos territorios se puede decir que el conocimiento pasivo avanza.

\subsection{El CONOCIMIENTO ACTIVO}

Si del conocimiento teóricamente pasivo pasamos al uso efectivo, el panorama cambia radicalmente. Aunque es cierto que, inexplicablemente, no tenemos datos estadísticos de este extremo tan crucial, todo el mundo admite que la impresión subjetiva que de él se tiene es fiable. Y la impresión subjetiva es, simplemente, alarmante. En efecto, desde hace ya unos años se viene constatando que el castellano se está convirtiendo en la lengua de relación de casi todo el mundo, especialmente de la juventud. El fenómeno es algo complejo, pero parece que se explica básicamente por el hábito adquirido durante los años del posfranquismo de hablar en castellano a cualquiera que no entendiera el catalán. Poco a poco el hábito dejó de tener fundamento teórico (acabamos de ver que todo el mundo entiende hoy la lengua) pero se consolidó de tal 
forma el automatismo de cambiar de lengua ante cualquier persona no claramente catalanohablante de origen, que hoy constituye una de las preocupaciones más serias de cuantos se ocupan de la lengua. Se ha dicho que nunca se había conocido tanto el catalán como ahora (en la escuela se enseña prácticamente a todo el mundo), pero que nunca se había utilizado tan poco. Ninguna mella han hecho contra la fatídica costumbre cuantas campañas han lanzado los políticos para que los catalanes habláramos el catalán en todas partes y en cualquier circunstancia. Hay algo más poderoso que las campañas: es la costumbre, pero sobre todo es la incomodidad de hablar en una lengua a otro que nos responde en otra que sabemos tan bien como la primera.

Este problema y el de la baja calidad de la lengua cuando se usa constituyen el tema central del libro más contundente aparecido en estos últimos meses: el de Prats-Rafanell-Rossich; pero nadie es ajeno a la alarma: Reixach se refiere a ella constantemente (páginas $5,135,143,144,147,148$ ), a pesar de no ser el tema de su estudio. Sólo Vallverdú quiere acallarla con malabarismos que no convencen y que incluso llegan al cinismo, si no al sarcasmo. Incluso ustedes pueden apreciar lo disparatadamente injusta que es una de las frases del capítulo de conclusiones del libro de Vallverdú (página 119): "en el peor de los casos, la lengua catalana va a durar tanto como sus vecinas -el castellano, el francés, el italiano-, puesto que no veo diferencias esenciales entre los problemas de aquélla y los de éstas en el respectivo proceso evolutivo." Para todo catalán que contemple los hechos con calma, esta sola frase desautoriza todo el libro de Vallverdú. La ha escrito como reacción al libro antes aludido, en que se expresa el temor de un rápido, inminente desenlace para nuestra lengua, temor que se basa en los fenómenos de que les acabo de hablar.

Ya ven ustedes cómo en nuestro dominio lingüístico se crispan los ánimos por esa criatura a todas luces delicada que se llama la lengua catalana: se pelean los lingüistas, se pelean los políticos, se pelean los sociolingüistas. A mi modesto entender, todo el mundo ve a esta criatura con la misma escasa esperanza, pero los hombres peleamos más unos contra otros que a favor o en contra de las cosas de fuera de nosotros, aunque el rubor nos hace poner los motivos en estas cosas externas.

Al final les diré qué remedios se han propuesto a tal situación. Veamos primero cómo está políticamente nuestra lengua.

\section{SITUACIÓN POLÍTICA}

El mundo de la política es difícil de entender y de interpretar si uno no está metido en él. Y lo que yo no encuentro justificado, por lo menos en gene- 
ral, es cargarse todo ese mundo en nombre de evidentes y hasta muy amargas contradicciones entre lo que los políticos dicen creer y defender y lo que hacen de hecho. Aquella frase de que la política es el arte de lo posible tendría que contribuir a calmar los desasosiegos de quienes podemos olímpicamente pasar de todo ese juego resbaladizo, porque trabajamos en algo que, esto sí, es totalmente superfluo para la vida diaria de la inmensa mayoría de las personas. Lo cual no significa que no podamos y debamos contribuir con nuestra opinión a la coherencia entre discurso y acción y a la convivencia entre las personas en general.

Los catalanes sabemos mucho de esas contradicciones, de este arte de lo posible. Sin ir más lejos y entrando en tema, nuestro Estatuto de autonomía, en su artículo $3 .^{\circ}$, define la situación legal de nuestra lengua. Observen que en su punto 2 hay una frase lingüísticamente incoherente (voluntariamente incoherente, puesto que lo es también en la versión catalana y además lo revelaron en su día los medios de comunicación). Dice: "1. La lengua propia de Cataluña es el catalán. 2. El idioma catalán es el oficial de Cataluña, así como también lo es el castellano, oficial en todo el Estado español." Había que conseguir que el catalán fuera oficial y que lo fuera con algún viso de preferencia, pero de ninguna forma se podía dejar entrever que el castellano no lo fuera o lo fuera en inferioridad de condiciones. $\mathrm{Y}$ ahí es donde los políticos imponen su razón contra incluso las del sentido común de la lengua.

Oigamos ahora la Constitución, también en su artículo 3.․: "I. El castellano es la lengua española oficial del Estado. Todos los españoles tienen el deber de conocerla y el derecho a usarla. 2. Las demás lenguas españolas serán también oficiales en las respectivas Comunidades Autónomas de acuerdo con sus Estatutos."

Los textos legales que definen el papel del catalán son la Constitución, los Estatutos de autonomía de las tres comunidades y sendas leyes llamadas de normalización lingüística. Varios decretos y sentencias perfilan los contornos siempre imprecisos de esas leyes. Veamos, pues, qué dice la ley de normalización de Cataluña. Artículo 2.: "El catalán es la lengua propia de Cataluña. Todos los ciudadanos tienen el derecho de conocerla y de expresarse en ella.... en las relaciones y en los actos públicos, oficiales y no oficiales."

Vayamos al grano. Muchas personas no aceptan ninguno de los tres textos. Algunos, los menos, no aceptan que el castellano tenga que ser obligatorio para nosotros: lo cual no es lo mismo que decir que no nos sea necesario hoy por hoy. Pero la inmensa mayoría no aceptan por lo menos otros dos puntos de la ley: no aceptan que el catalán no tenga que ser también obligatorio en su propio territorio (y estrictamente hablando no lo es. "Todos los ciudadanos tienen el derecho" pero no la obligación de conocerlo), pero sobre todo no aceptan que el castellano tenga que ser cooficial allí. Hay, por tanto, tres nociones diferentes: necesario, obligatorio y oficial. Los más radicales aspiran a que el catalán sea la única lengua pública de Cataluña; 
desde luego, no a sangre y fuego (desde los remotos tiempos de los almogávares, nunca los catalanes hemos sido violentos), ni siquiera dañando en lo más mínimo los derechos de toda persona a su propia lengua y cultura. Me estoy refiriendo, claro está, a los muchos miles de personas que no han nacido en nuestro ámbito linguístico y cuyas lengua y cultura propias de origen no son el catalán.

Yo no soy sociolingüista y fácilmente podría perderme en esta encrucijada. Intentaré tan sólo decirles dónde está la clave de la divergencia de posiciones. Los actuales textos legales parten del pie forzado por la Constitución, de que en España hay una lengua soberana indiscutible y de que las otras "serán objeto de especial respeto y protección". Es muchísimo, comparado con lo que había. Pero es insuficiente. ¿Por qué? Las leyes que nos rigen, con su articulado intentan crear unas condiciones adecuadas para que el gallego, el vasco y el catalán puedan seguir ahí sin persecución explícita como en otros tiempos; sin que ningún facha pueda escupirte a la cara, en tu propia casa, aquello - y perdonen ustedes, que nada tuvieron que ver con la agresión- de "Hable usted en cristiano!". Pero no crean las condiciones suficientes para que estas lenguas puedan hacer frente, después de siglos de persecución feroz y en gran parte eficaz, a las brutales condiciones en que hoy les toca vivir. Nuevamente perdonen: Ilamo brutales a las condiciones políticas, económicas y demográficas actuales $y$, desde luego, no busco culpables de la situación: me limito a sacarla del posible olvido. Suscribirían mi rudo adjetivo ciertos Estados europeos, demográficamente inferiores incluso al pueblo catalán, que tienen que defender sus propias lenguas frente al inglés. Lo suscribirían también los franceses de Quebec. Sólo queremos ignorarlo, legalmente, nosotros. ¿Se trata de una debilidad política?

Para un madrileño parecerá una actitud arrogante, insensata, ridícula o por lo menos incomprensible. Y lo es desde el punto de vista político: en definitiva, nadie regala nada a nadie y todo lo que se obtiene es fruto del forcejeo entre los designados para ese juego, pero previamente tiene que haber poder real por parte de quien reclama, de lo contrario una sonrisita benévola y una palmadita en la espalda calman la impaciencia. Quiero decir que si los catalanes no tenemos más es, casi seguro, porque no podemos exigir más, porque nuestro poder es pequeño. Nuestra actitud tiene que ser, pues, incomprensible para ustedes políticamente hablando. Pero lingüísticamente hablando, no: todo depende del objetivo que se pretenda. Si sólo se pretende dejar de molestar a esas lenguas, todo está ya bien. Si se pretende salvar de verdad a esas lenguas, no es suficiente.

Sin embargo, no todo el mundo cree que la razón de la precariedad legal esté únicamente en el forcejeo político. Muchos, y yo entre ellos, creen que hay otra razón más decisiva, nunca confesada por amarga y políticamente dañina. La razón profunda de que las lenguas de España no tengan un estatuto más alto es que nadie cree en ellas. No creen, evidentemente, quienes no tienen por qué creer, los "otros" españoles. Pero no creen tampoco quienes las 
hablan, excepto media docena de profesionales que vivimos de ellas o alrededor de ellas. Por tanto, el problema se agrava. Oí una vez al prestigioso sociolingüista de Quebec el señor Corbeil que no hay que sobrevalorar el poder, el valor personal o el papel público de los políticos: éstos, en el mejor de los casos, no son más que la quintaesencia del pueblo que los votó. Si el pueblo, como digo, no cree, de verdad, en su lengua...

Tampoco sé si las lenguas son algo en que de verdad se pueda creer. No sé si un banquero, el jefe de un supermercado de alimentación, el presidente del Comité Olímpico Internacional o el secretario general de Comisiones Obreras pueden creer en el catalán hasta los límites en que yo les he planteado el problema. Claro que otros les dirán que cómo van a creer en sus lenguas unos pueblos que han sido sistemáticamente y sutilmente educados para que no creyeran; y que, por tanto, hay que exigir del político una acción más eficaz de la que hipotéticamente el pueblo quizá reclame. Etcétera, etc. Como ven, la tela de araña nos está envolviendo. Por tanto, voy a dejarlo aquí. Pero opino que en España no se adelantará definitivamente en el terreno de la paz lingüística hasta que se hayan planteado abiertamente y sin cortapisas ciertos aspectos incómodos: incómodos para el poder central, incómodos de hecho para cualquier poder regional, incómodos para los mismos catalanes, gallegos y vascos que mantienen ideologías radicales.

Ya que no puedo discutir el asunto con argumentos científicamente contundentes, permítanme que por lo menos les cuente, muy brevemente, algunas anécdotas sobre nuestra pretendida normalización lingüística, que pueden contribuir a aclarar nuestro pensamiento.

Hasta hace un par de años en las oposiciones para el cuerpo de magisterio de Cataluña (mucho menos de Valencia y Baleares) no se exigía saber catalán. En consecuencia teníamos las siguientes situaciones kafkianas. Por una parte, los catalanes teníamos derecho a ser educados en catalán; pero el magisterio no tenía obligación de saberlo. Por otra parte, en las escuelas del magisterio catalanas se exigía el catalán en el currículo: como en algunas escuelas los aspirantes eran en gran proporción no catalanohablantes (sobre todo en el cinturón de Barcelona, donde hay dos de estas escuelas), el catalán era el potro de tortura para muchos, que terminaban la carrera y lo arrastraban dos y tres años, y al final pasaban a trancas y barrancas; pero el cinismo estaba en que sus colegas de Valladolid o Salamanca, libres del potro, podían venir a Cataluña a opositar mientras ellos se quemaban las cejas ante aquella lengua que forzosamente se les tenía que hacer odiosa. Nuestra Administración no sabía qué hacer, maniatada por la regulación superior o por el miedo que tanto papel desempeña en épocas de tensión. Los departamentos de catalán obligaron a romper el absurdo a base de campañas largas que incluso llegaron a la TV. Y fue entonces cuando los políticos se vieron obligados a imponer el catalán en las oposiciones. Como es natural, no confesaron que no era mérito suyo, sino que se pusieron la medalla en lugar bien visible. 
La segunda anécdota terminó hace un mes y medio o dos. Nuestra Administración no podía exigir el conocimiento del catalán a sus funcionarios, aunque estatutariamente el catalán es lengua oficial en nuestra Administración y aunque el ciudadano tiene derecho legal a usar el catalán en ella, etcétera. Los recursos de insconstitucionalidad "disuadían" de cualquier acción tendente a cuadricular el círculo. Como les digo, finalmente el Tribunal Constitucional nos ha dado la razón.

¿Podemos respirar? De ninguna manera, colegas de Alcalá: quienes tenemos la desgracia de hablar lenguas poco importantes nunca podemos respirar. Sin inventarme nada, la tercera anécdota se lo hará ver. Se trata del distrito único universitario. Según esa genial idea, todos los estudiantes universitarios podrían ir a cualquier universidad del Estado. Naturalmente, exigirían que se les enseñara en la lengua del imperio, y nuevamente perdonen ustedes, dejen que el conferenciante no se reprima continuamente. Adiós años de esfuerzos para conseguir que el catalán vuelva a sus naturales derechos universitarios... Naturalmente, estas ideas salen de ministerios directamente obligados a proteger la cultura. Naturalmente, las universidades son la cúpula de la cultura. Pero no menos naturalmente, nuestras lenguas no son cultura, son molestos y pertinaces bultos que le salen a la cultura.

Aun sin la cortapisa del distrito único, bastantes problemas universitarios tienen ya nuestras lenguas. Piensen tan sólo en los intercambios de los programas Erasmus.

Vayamos de nuevo a la raíz del malentendido, pues ésta es la misión de los universitarios. Una parte de la raíz se encuentra en el artículo 14 de nuestra carta náutica, que reza así: "Los españoles son iguales ante la ley, sin que pueda prevalecer discriminación alguna por razón de nacimiento, raza, sexo, religjón, opinión o cualquier otra condición o circunstancia personal o social." (Entre paréntesis, ¿no les sorprende que no se mencione la "razón” de la lengua, quizá la única que el legislador debía de tener en la mente?) Otra parte de la raíz está en la interpretación que hasta ahora, y unánimemente, se ha dado al artículo. La interpretación ha sido siempre desfavorable a las lenguas periféricas de nuestra piel de toro. La primera excepción ha sido la que les he dicho del Tribunal Constitucional.

¿Va a negar usted que todos los españoles somos iguales? De ninguna manera. ¿Cómo voy a negarlo, señores, si precisamente ésta es la única y quizá la última tabla de salvación de las minorías? Todos somos iguales, sí señor; lo que ocurre es que en nuestra España - y en nuestra Europa y en nuestro mundo- del final del siglo XX unos somos más iguales que otros. Si yo necesito que en mi oficina se sepa escribir una carta en alemán, usted que sabe alemán será exactamente igual ante la ley que su contrincante, pero tendrá usted más méritos y ganará la plaza. Si las escuelas y la Administración de Cataluña necesitaban, incluso legalmente, que sus funcionarios supieran catalán... han tenido que pasar muchos años para que el mérito no se interpre- 
tara como "discriminación". Podríamos añadir la coletilla que para no "discriminar" a los "otros" españoles, se nos discriminaba a nosotros. Pero ya no hace falta; no era justicia lo que en la mente de muchos anidaba: era voluntad inquebrantable de que esas lenguas no pudieran salir adelante.

Voy a terminar asumiendo una reclamación del sociolingüista catalán más competente y lúcido, Lluís Aracil, ya compartida por otros (véase Bastardas 22). Aracil lleva años reclamando una ley lingüística de ámbito estatal. Porque es muy cómodo abandonar a las comunidades autónomas a sus propios destinos (aunque prestándoles una mochila provista de pan y vino). Pero el mal endémico de España en el aspecto lingüístico requiere que tome cartas en el asunto el propio Estado.

Veamos brevemente cuáles son las principales propuestas que han hecho los autores para evitar el desastre anunciado, o por lo menos para retrasarlo.

\section{PROPUESTAS Y CONCLUSIONES}

Ya sabemos cuál es el peligro. En palabras de Prats-Rafanell-Rossich (página 82), que suscriben otros autores (por ejemplo, Royo) y yo también, "si no se opera un cambio radical, no vamos a tardar muchos años en llegar a una situación irreversible": la de desaparición del catalán, por lo menos como lengua pública y de cultura. Veamos algunas de las propuestas recientes.

a) Reixach llama la atención sobre el enorme capital linguístico que puede representar la actual juventud, escolarizada ya en catalán, cuando se incorpore al mundo laboral. Hay que evitar, dice, "el riesgo de que esta virtualidad sea absorbida y anulada por la situación anterior" (página 144). Por otra parte, este autor ha comprobado que el menor conocimiento del catalán coincide con la clase social menos culta (en general, personas inmigradas); y por tanto, sugiere complementar las medidas de apoyo directo a la lengua con otras indirectas, que consistirían en elevar el nivel cultural de una parte de nuestro pueblo (páginas 146-147).

b) Royo abre una vía absolutamente nueva de opinión. Lo que Reixach interpreta como falta de cultura en las clases más bajas, para Royo es una actitud social de las clases más pudientes catalanas, consistente en parapetarse detrás de "su" lengua para mantener a los otros reducidos a trabajar y callar. Más o menos. Este autor va al grano sin rodeos ni hipocresías: para que el catalán subsista tiene que adquirir tres millones más de hablantes dentro de su propio territorio, y esto significa 
romper drásticamente la tradición de hacer del catalán un signo de identidad ( $y$, como he dicho, de clase) y un "patrimonio" sacrosanto, para lograr que sea moneda de mercado, sin más interés: de usar y tirar. Lo cual significa, claro está, dictar leyes adecuadas y dejarse de las teorías voluntaristas y resistenciales que han durado un siglo y medio.

c) Bastardas pone también directamente el dedo en la llaga y, después de constatar que la política lingüística se ha dirigido hasta ahora principalmente a convencer a los catalanes de que nos esforzáramos individualmente, advierte que los únicos correctivos en los que podríamos cifrar alguna esperanza serían estos dos: intentar mejorar las condiciones legales (es decir, cambiar las leyes) y hacer una política encaminada a cambiar los hábitos de las instituciones, tanto públicas (en las que ya se ha hecho algo) como privadas (al estilo de lo que se ha tenido que hacer en Quebec), puesto que las instituciones son las que realmente pueden arrastrar a los individuos a cambiar de hábitos.

d) Por su parte, Prats-Rafanell-Rossich apuestan por una renovación del viejo y gastado discurso catalanista: se trataría, simplemente, de interesar de verdad a la juventud, nativa o inmigrada, en un proyecto de futuro que incluya la lengua "como marca de un deseo - bien legítimo- de soberanía, con un programa integrador de emancipación nacional y de progreso", dicen (página 78). Por otra parte, estos tres autores rechazan totalmente la actual política llamada de "bilingüismo pasivo": rechazan el bilingüismo porque todos los sociolingüistas han dicho hasta la saciedad - y nosotros lo vemos con nuestros ojos impotentes- que es un sistema que acaba irremisiblemente en la desaparición de la lengua más débil; y rechazan el bilingüismo pasivo porque lo único que ha conseguido durante estos años es hacer bilingües activos a los catalanohablantes, mientras dejaba como monolingües activos a los castellanohablantes, precisamente a los que había que ganar para la lengua. Todavía más explícitamente y de manera más argumentada y contundente rechaza las diferentes clases de bilingüismo Royo (páginas 42-43, 93-103).

e) Prats-Rafanell-Rossich añaden (páginas 79-82) que nuestros políticos deben cuidar muy especialmente que en el actual proyecto europeo la cuestión del ordenamiento lingüístico no quede como un residuo sin importancia. Royo (página 37) precisa más: los catalanes nos complacemos masoquistamente en considerar a nuestra lengua "la más importante de las lenguas no oficiales", cuando lo que hay que conseguir es que sea una de las oficiales en Europa, aunque sea la última. (Por cierto que el primer paso para este objetivo ya se ha dado. en sentido muy favorable: el catalán ha sido reconocido recientemente como lengua oficial de las comunidades europeas.) 
Para terminar, recordemos el principio básico de la supervivencia de las lenguas. Las lenguas son como los demás valores del intercambio humano: sólo interesan, sólo pueden resistir si son útiles y necesarias. He aquí el gran reto: conseguir que sean útiles y necesarias por lo menos en su propio territorio. Pero estas palabras no son palabras de adorno, son un reto político y social importante que no me atrevería a formular en un ambiente menos tolerante para las utopías que el de esta antigua, civilizada y prestigiosa Universidad de Alcalá. Les ruego que se armen ustedes de valor, porque la fórmula no es fácil de digerir: nuestras lenguas minoritarias sólo serán útiles y necesarias en su territorio en la medida en que deje de serlo el castellano. Este reto sólo se puede plantear, claro está, si de verdad, no sólo en el articulado, este país quiere salvar estas lenguas y proyectarlas llenas de vigor hacia el futuro de Europa.

A cualquiera que oiga estas palabras no se le escapará que una lengua no es algo que vaya solo por el mundo. Nuestras lenguas, para sobrevivir, necesitan condiciones políticas y sociales excepcionales, sí; pero también tendrán que luchar contra unas condiciones económicas y tecnológicas hoy dificilísimas. En esta conferencia nada he dicho de las condiciones económicas, de las enormes masas de turistas que imponen sus leyes linguísticas implacables en Cataluña, Baleares y País Valenciano; nada de la lucha por controlar el infinito poder de la información, en un mundo en que ésta es más importante que la energía (véase el excelente e impresionante libro de Josep Gifreu). Estos factores, sin embargo son tan importantes como los analizados y son inseparables de ellos. Las preguntas con que inevitablemente hay que terminar son éstas: ¿Querrán nuestras comunidades hacer frente a una problemática tan grave, urgente y compleja? ¿Podrán?

\section{BIBLIOGRAFÍA CITADA}

Actes: Direcció General de Política Lingüística i Institució de les Lletres Catalanes: I Jornades sobre Llengua i Creació Literària. Barcelona, 19 i 20 de gener de 1990. Actes. Generalitat de Catalunya, Barcelona, febrero 1991.

BASTARDAS I BOADA, Albert: “L'extensió de l'ús del català: fonaments teòrics per a una nova etapa", Revista de Catalunya (Barcelona), 38 (febrero 1990), pp. 13-23.

Burguera, Francesc de P.: És més senzill, encara: digueu-li Espanya. Eliseu Climent, València, febrero 1991.

Gifreu, Josep (director): Comunicació, llengua i cultura a Catalunya, horitzó 1990. Institut d'Estudis Catalans, Barcelona 1986.

JOAN I MARí, Bernat: El progrés detonant de la substitució lingüística. Can Sifre, Eivissa 1991. 
Mapes per a l'estudi de la llengua catalana, Revista Com (Barcelona), Suplement núm. 6, Generalitat de Catalunya, Barcelona, diciembre 1989.

Pvos. María Lluïsa: L'amenaça del català "light". Tibidabo, Barcelona, octubre 19y). 2." ed., diciembre 1990.

Prats, Modest, Rafanelt, August, Rossich, Albert: El futur de la llengua catalana. Empúries, Barcelona, noviembre 1990. Existe 3. ed. (abril 1991).

ReIXACH I Pla, Modest: Difusió social del coneixement de la llengua catalana. Anàlisi de les dades lingüistiques del padró d'habitants de 1986, de Catalunva, Illes Balears $i$ Pais Valencià. Generalitat de Catalunya, Barcelona, octubre 1990.

Royo, Jesús: Una llengua és un mercat. Edicions 62, Barcelona, marzo 1991.

SABATER, Ernest: Ni "heavy", ni "light": català modern! Empúries, Barcelona, marzo 1991.

VAll.Verdú, Francesc: L'ús del català: un futur controvertit. Edicions 62, Barcelona. octubre 1990. 